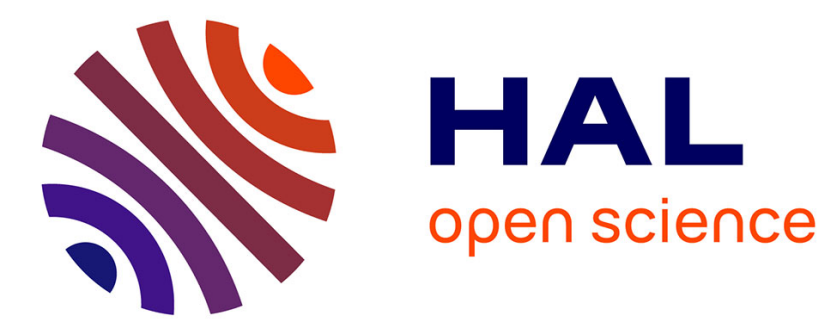

\title{
Why not OSI?
}

Bill Davey, Robert F. Houghton

\section{To cite this version:}

Bill Davey, Robert F. Houghton. Why not OSI?. IFIP International Conference on the History of Computing (HC), May 2016, Brooklyn, NY, United States. pp.115-121, 10.1007/978-3-319-49463$0 \_8$. hal-01620133

\section{HAL Id: hal-01620133 https://hal.inria.fr/hal-01620133}

Submitted on 20 Oct 2017

HAL is a multi-disciplinary open access archive for the deposit and dissemination of scientific research documents, whether they are published or not. The documents may come from teaching and research institutions in France or abroad, or from public or private research centers.
L'archive ouverte pluridisciplinaire HAL, est destinée au dépôt et à la diffusion de documents scientifiques de niveau recherche, publiés ou non, émanant des établissements d'enseignement et de recherche français ou étrangers, des laboratoires publics ou privés. 


\title{
Why not OSI?
}

\author{
Bill Davey $^{1}$ and Robert F. Houghton ${ }^{2}$ \\ ${ }^{1}$ RMIT University, Melbourne, Australia. ${ }^{2}$ Idaho State University, USA \\ Bill.Daveyermit.edu.au, hougrobedisu.edu
}

\begin{abstract}
This paper presents an argument that the OSI proposed standard is technically superior to the TCP/IP standard for network communications. An Actor-Network Theory approach is taken for analysis of the historical record surrounding the adoption of TCP/IP. The paper does not seek to create a new history of TCP/IP but to suggest this is a case where traditional explanations of adoption based on the nature of the technology do not explain the demise of the OSI model. Parallels are then drawn between this adoption and the possible problems with the implementation of IPV6. These parallels provide insight into the impediments that may arise with the adoption of the new standard.
\end{abstract}

Keywords. Internet, OSI model, TCP/IP, IPV6, adoption, actor-network theory

\section{Introduction}

This paper first argues that the current TCP/IP standard for Internet communications is technically inferior to the parallel OSI standard. The historical record is then analysed to identify both the actors that were involved with the adoption of the standard and the process of adoption that occurred. This is not an attempt to create a new history of TCP/IP, as several robust histories exist. The aim of the paper is to examine the adoption of TCP/IP over a superior technology as an example of an adoption story where the nature of the technology does not explain the adoption. In this way we place the adoption of TCP/IP as being similar to the stark example of VHS tape winning over the superior BETAMAX standard. The paper then asks the reader to consider the example of IPV6 as another possible adoption where technical considerations may not determine the future.

\section{A Quick Timeline of the Internet}

A selection of highlights of the introduction of the Internet provides some context for this discussion. These points in history are chosen to provide some sense of the evolution of the technologies and some of the uses proposed and enacted. Some trace the very first thoughts to a paper by Licklider [1] who proposed a 'Galactic Network' that would allow access to data and software from anywhere in the world. Licklider was the first head of the computer research program at the Defence Advanced 
Research Projects Agency (DARPA) [1] and convinced succeeding players at DARPA that this concept was important. The first papers on packet switching, an essential technology, are attributed to Leonard Kleinrock [2] [3, 4]. In 1969 the first host computer was installed at UCLA, enabling the start of ARPANET [1]. This first instance of an Intenet like network used Network Control Protocol (NCP), a host-tohost protocol. ARPANET was introduced to the public in 1972 and email was seen as the 'killer ap' [1, 5]. By 1975 there were more than 100 nodes on ARPARNET. NCP was designed as a protocol for a single network. As other networks emerged there was a need, perhaps driven by a desire to have email delivered between networks, to allow messages to pass between networks. In January 1983 ARPANET changed the host protocol from NCP to TCP/IP. This change allowed ARPANET to be split into military and research networks [1]. As other networks changed to TCP/IP they were able to share research and deliver email to each other. By 1985 a recognisable Internet existed using TCP/IP as the protocol. A useful breakdown is that of the eras of packet switching, purpose built networks and then the World Wide Web. Figure 1, taken from Mowery and Simcoe [5].

\begin{tabular}{|l|l|}
\hline \multicolumn{1}{|c|}{ Time Period } & \multicolumn{1}{c|}{ Critical Developments } \\
\hline $1960-1985$ & $\begin{array}{l}\text { Invention of digital packet-switching and associated } \\
\text { standards/protocols } \\
\text { Birth of Internet self-governance institutions }\end{array}$ \\
\hline $1985-1995$ & $\begin{array}{l}\text { Growth of NSFNET and parallel private } \\
\text { infrastructure } \\
\text { Growth in installed base of PC's and LAN's }\end{array}$ \\
\hline $1995-$ Present & $\begin{array}{l}\text { Diffusion of the World Wide Web } \\
\text { Privatization of Internet infrastructure and } \\
\text { commercialization of Internet content }\end{array}$ \\
\hline
\end{tabular}

Fig. 1 (from [5] )

\subsection{Discarded Alternatives}

Most early networks were purpose built. Leiner et al, [1] identifies MFENet and HEPNet for physics researchers, the NASA Span network and the academic CSNET. With the free distribution of Unix to academic institutions the built in UUCP protocol was the basis for BITNET built in 1981 to link academic mainframe computers in several countries. Some commercial companies attempted to establish standards around networks of their own computers such as the Xerox XNS, Digital Equipment's DECnet and the IBM SNA. Of course these networks did not favour interoperability 
with other networks and this failure meant they remained islands. At this time no-one had an interest, commercial or research, in progressing OSI to a working standard.

\subsection{OSI vs TCP/IP vs The Bad Guys}

The Internet is the network of networks. A network is a series of nodes interconnected to exchange information. The Open Systems Interconnect (OSI) model is a seven layer model designed to define the different parts of network communication. Each layer has a distinct and important function.

\begin{tabular}{|l|l|}
\hline Layer Name & Role \\
\hline \hline Physical & Media in which data is transmitted \\
\hline Data Link & Standards by which data is bundled and transmitted \\
\hline Network & Standards that connects diverse networks together \\
\hline Transport & Protocols that manage transmission of data \\
\hline Session & Controls the connections between nodes \\
\hline Presentation & Provides translation or syntax \\
\hline Application & Displays data to user \\
\hline
\end{tabular}

Chart 1. The OSI Model

The other model used to assign data transmission is the TCP/IP model

\begin{tabular}{|l|l|}
\hline Layer Name & Roll \\
\hline \hline Network/Link & Defines methods of connecting nodes \\
\hline Internet & Creates datagrams and routes to networked nodes \\
\hline Transport & Provides communication services from node-to-node \\
\hline Application & $\begin{array}{l}\text { Contains highest level of communication for the data } \\
\text { transmission }\end{array}$ \\
\hline
\end{tabular}

Chart 2. The TCP/IP Model

Due to the fact that TCP/IP has become the standard on which the Internet works, the TCP/IP model is taught by network professionals. The OSI model is presented in comparisons to the TCP/IP model. However in a world with growing computer security threats, the OSI model is more relevant to the knowledge of IT workers. The OSI model provides a complete framework on which IT security professionals can refer to diagnose the application, source, and method of attack.

De Vivo et. al. [6,7] discuss methods of Internet security. All of their efforts discuss, explore, and explain methods of Internet attack. These papers show vulnerabilities in the TCP/IP stack. While these papers are in depth and are prime examples of security research, not one of them discuss attack methods at the physical network level. Different media require different approaches to security. A stray radio wave is much harder to defend over a buried fibre optic line. An example of this 
would be when, in 2008, the Associated Press reported that a major Internet cable was cut in the bottom of the ocean. While De Vivo et. al. [6, 7] might call this a service attack due to the fact that the Internet is not available, TCP/IP does not have a proper method of classification.

\section{Research Method}

The historical record of all standards is rich as the original meeting minutes for standards organisations are available. In addition historical analysis of the introduction of standards has been performed by a number of studies from different viewpoints. On top of this literature there are many commentaries on both the historical record and the forces at play. In identifying actors and interactions these sources were studied for repeated identification of the same actors and rich descriptions of relationships between them.

The study of a communications standard is particularly relevant to a materialsemiotic approach [8] as the communications layer is intended to be beneath the notice of the user. It is also apt in the historical context as communication between the humans was dependent on the existence of a standard for communication. This 'sine qua non' vicious circle is an entertaining aspect of the analysis.

The analysis was conducted by two very disparate researchers: one elderly Australian with a systems background and one younger American with a networking background. This allowed independent reading of sources with researcher meetings to discuss and decide upon a 'middle ground' and the conservatism arising from this approach may be evident in the outcome.

The method taken was to first identify significant actors: humans, technologies and organisations. This analysis is not intended to be a comprehensive analysis of the whole story of TCP/IP but to identify divergences from the adoption of a possible OSI model based alternative.

\subsection{The History of OSI and TCP/IP}

TCP/IP actors arose in both Europe and the United States through the 1970s. Universities in London, Manchester, Bristol and Edinburgh were reflecting the energies being expended in DARPA and the universities in the USA. On both continents the initial standards were those of Unix and X.25 communications [9] . These protocols were frustrating to the visions of most of the players in producing a wider, more open architecture. Leiner et al. [1] identify the move of Dennis Jennings to lead the American NSFNET program as a crucial point in the move to adopt TCP/IP. At almost the same time Reid [9] suggests that the UK JANET network had become so unworkable that a decision was made to adopt TCP/IP in the form of the Janet IP Service (JIPS). These adoptions of the standard resulted in massive increases in use of the networks. Reid [9] estimates that TCP/IP traffic in the JIPS system exceeded the X.25 traffic within 10 months of the introduction. 
The OSI protocol suite was proposed and discussions started in 1978 [2]. This suite would encompass all the requirements placed upon it by the multitude of stakeholders. As late as 1988 the Internet Engineering Task Force (ITEF) issued a memo stating that all government computers would use OSI. [3]

In 1990 Tim Berners-Lee invented the World Wide Web application [4]. By this time it was clear that the OSI protocol suite was lagging behind the development needs of the Internet. TCP/IP was already in use for the connection and transmission of data.

As the use of the Internet grew, the need for computers to connect with each other in a common standard was overwhelming. TCP/IP was in place and OSI was still being developed. TCP/IP became the de facto standard for all data transmissions on the Internet.

\subsection{The Demise of OSI}

OSI had been considered and rejected for the JANET network $[9,10]$. No other actor seemed interested in developing a new standard on the basis of OSI. The very large actor identified by some historians was the funding from USA Government agencies. The National Science Foundation (NSF) contributed large amounts of money as did the various aspects of DARPRA. The money issue is reported by Reid [9] in terms of the problems of funding even the telephony charges that Universities in Britain found mounting. Of course an open standard that allowed computers from IBM and DEC to connect with no licence charges should be seen in the context of funding as an actor. A research or academic institution could use the low cost BSD Unix and the open standard to immediately join the Internet. The value of Unix as an actor should also not be discounted. As the low fee BSD Unix was available to the enquiring minds of University students a plethora of utilities became available that reinforced the value of Internet connections. The value of money as an actor became stark when, in 1985 the NSF mandated that funding for Internet connection in Universities would only be available if TCP/IP was used [5] . The size advantage of ARPANET was almost guaranteed from that point on.

One would expect the support for OSI to come from standards organisations but a set of actors joined the discussion in the form of credible standard setting committees. These included the Internet Configuration Control Board (ICCB) formed by the then DARPA Director. This later became the Internet Activities Board (IAB) and absorbed the Internet Engineering Task Force (IETF). Eventually, in 1992, the work of these bodies was co-ordinated by the Internet Society (ISOC) [5]. These actors should be seen in opposition to the standards bodies, mostly in the telecommunications area, which had been advocating X.25 as the standard for the communication protocol, and might have been able to advocate for OSI if there had been an alternative.

A more recent development has seen that OSI is still being taught in conjunction with TCP/IP in academic network theory classes. The top selling textbook on Amazon: Computer Networks (by Tanenbaum) [11], contains an extensive section on OSI and how it can be used to help differentiate network layers. In fact a search of 
networking textbooks shows that the top ten search results in books.google.com each contain at least a section if not a chapter on OSI.

\subsection{Format Wars}

Every technology that fails still enhances the future use of technology. One of the first technologies that begat a standardisation issue was the differences between alternating current and direct current. Thomas Edison was trying to convince the public that DC power would provide electricity better than AC. In using the vastness of his technology to promote his views on power in Electrocuting an Elephant, in 1903 Edison showcased the destructive force of AC current [12] . Eventually events proved that $\mathrm{AC}$ power could be carried further long distances but DC power would be the preferred method for electronic devices.

An example of competing formats is the very famous VHS verses Betamax wars. This video standard saw that VHS won the consumer market. Betamax was still widely used and only stopped production in 2015 . This was due to the fact that Betamax recorded higher resolutions. Betamax found a niche in midsized television stations as a lower cost but high quality recording methodology. This format also allowed its creator, Sony, to enhance its audio cassette tapes until the arrival of digital media finally caused the demise of most tape recorders.

These wars still go on today as witnessed by the various Apple operating systems against their more prevalent competitors. In the 1980 through the 1990s Apple and Microsoft competed over the desktop computer marketplace with Apple almost going bankrupt in 1997. However by 2006 Apple rebounded to create the iPod and later the iPhone revolutionizing mobile computing. By 2011 Google's android mobile operating system had over 50\% of the world's market share [13].

\section{Conclusion}

At its core, OSI was a rejected technological solution. Reasons include that, at the time, TCP/IP could handle all the communication necessary, was already deployed on the majority of systems, and was fully complete. None of these are factors that would arise form an analysis that did not consider the actors and their interactions. As the Internet evolved into the mass-market that we use today, security was an afterthought, not actively considered The lack of consideration of strong structural issues can be seen as a result of the actors involved in the initial stages of adoption. These actors were not envisaging a system serving the needs of the current Internet that even involved banking transactions. TCP/IP continues to have significant security issues and these are solved by 'work-arounds' that would not have been needed in an OSI based system. More research is needed into using OSI as a security model replacement for TCP/IP.

The analysis here is ex post facto but there is a modern issue that could be analysed in the same fashion. IPV6 [14] has been designed to overcome many of the architectural problems of TCP/IP. This superior technology has not been adopted at 
the rate anticipated despite the potential problems of diminishing IPV4 space [15-17] . Some problems with the implementation of IPV6 are technical, for instance the difficulty of changing V4 addresses that are hard coded. Authors have also addressed the question of interactions between actors - especially between ISPs and between customers and ISPs [18]. It is possible to characterize a set of problems with the adoption of V6 as "it is working now why should I change". This pragmatic approach to technology relates strongly to our analysis of the OSI model - a technology is in place that has faults, but the actors have a strong interaction with that technology and their inertia, or their investment in the inferior technology. This means that the prospect of examining a better technology and "starting again from scratch" is never likely to happen.

\section{References}

1. Leiner, B.M., et al., A brief history of the Internet. ACM SIGCOMM Computer Communication Review, 2009. 39(5): p. 22-31.

2. Leonard, K., Communication nets: Stochastic message Flow and delay. 1964, McGrawHill.

3. Kleinrock, L., Queueing Systems Vol: II: Computer Applications. 1976: John Wiley \& Sons, Incorporated.

4. Kleinrock, L., Information flow in large communication nets. RLE Quarterly Progress Report, 1961. 1.

5. Mowery, D.C. and T. Simcoe, Is the Internet a US invention? - an economic and technological history of computer networking. Research Policy, 2002. 31(8): p. 13691387.

6. De Vivo, M., et al., Internet vulnerabilities related to TCP/IP and T/TCP. ACM SIGCOMM Computer Communication Review, 1999. 29(1): p. 81-85.

7. De Vivo, M., G.O. de Vivo, and G. Isern, Internet security attacks at the basic levels. ACM SIGOPS Operating Systems Review, 1998. 32(2): p. 4-15.

8. Law, J., Actor network theory and material semiotics. The new Blackwell companion to social theory, 2009: p. 141-158.

9. Reid, J. The Good Old Days: Networking in UK Academia 25 Years Ago. [PDF] 2008 [cited 200816 April 2008].

10. Cooper, b., From Janet to SuperJanet: The Development of a High Performance Network to Support UK Higher Education and Research. 1990, The Computer Board for Universities and Research Councils.

11. Tanenbaum, A.S., Computer networks, 4-th edition. ed: Prentice Hall, 2003.

12. Daly, M., Topsy: The Startling Story of the Crooked Tailed Elephant, PT Barnum, and the American Wizard, Thomas Edison. 2013: Grove/Atlantic, Inc.

13. Oswald, E. Android Market Share Growth Accelerating, Nielsen Finds. PC World 2011 Feb 2015]; Available from: http://www.pcworld.com/article/226339/android market share g rowth accelerating nielsen finds.html

14. Deering, S.E., Internet protocol, version 6 (IPv6) specification. 1998. 
15. Nikkhah, M., Maintaining the progress of IPv6 adoption. Computer Networks, 2016. 102: p. 50-69.

16. Southworth, J.B., An empirical analysis of the relationship between IPv6 readiness, IPv6 enablement, and IPv6 effectiveness at colleges and universities in the United States. 2016, INDIANA STATE UNIVERSITY.

17. Zamani, A.T. and J. Ahmad, IPv6 Adoption: Challenges \& Security. IJCER, 2014. 3(1): p. 08-12.

18. Nikkhah, M., C. Dovrolis, and R. Guérin. Why didn't my (great!) protocol get adopted? in Proceedings of the 14th ACM Workshop on Hot Topics in Networks. 2015. ACM. 